\title{
Prediction of future falls in a community dwelling older adult population using instrumented balance and gait analysis
}

\section{Prädiktion von Sturzereignissen in einem Kollektiv selbständig lebender Älterer mittels instrumenteller Gang- und Gleichgewichtsanalyse}

Christoph Michael Bauer MSc 1,*,2

Phone +49-(0) 9131-822-3702

Email christoph.bauer@zhaw.ch

Ines Gröger $\mathrm{MD}^{1}$

Roland Rupprecht $\mathrm{PhD}^{3}$

Phone +49-(0) 9131-8528-8530

Email roland.rupprecht@fau.de

Valentine Leslie Marcar $\mathrm{PhD}^{2}$

Prof. Dr. Karl Günter Gaßmann MD $^{1}$

Email karl.gassmann@waldkrankenhaus.de

1 Geriatrics Centre Erlangen, Medicine III, Waldkrankenhaus St

Marien, Rathsberger Str. 57, 91054 Erlangen, Germany

2 School of Health Professions, Institute of Physiotherapy, Research and Development, Zurich University of Applied Sciences, Technikumstr. 71, P.O. Box, 8401 Winterthur, Switzerland

3 Institute of Psychogerontology, Friedrich-Alexander University of Erlangen- Nuremberg, Kobergerstr. 62, 90408 Nuremburg, Germany 


\section{Abstract}

\section{Background}

The role of instrumented balance and gait assessment when screening for prospective fallers is currently a topic of controversial discussion.

\section{Objectives}

This study analyzed the association between variables derived from static posturography, instrumented gait analysis and clinical assessments with the occurrence of prospective falls in a sample of community dwelling older people.

\section{Methods}

In this study 84 older people were analyzed. Based on a prospective occurrence of falls, participants were categorized into fallers and non-fallers. Variables derived from clinical assessments, static posturography and instrumented gait analysis were evaluated with respect to the association with the occurrence of prospective falls using a forward stepwise, binary, logistic regression procedure.

\section{Results}

Fallers displayed a significantly shorter single support time during walking while counting backwards, increased mediolateral to anteroposterior sway amplitude ratio, increased fast mediolateral oscillations and a larger coefficient (Coeff) of sway direction during various static posturography tests. Previous falls were insignificantly associated with the occurrence of prospective falls.

\section{Conclusion}

Variables derived from posturography and instrumented gait analysis showed significant associations with the occurrence of prospective falls in a sample of community dwelling older adults. 


\section{Zusammenfassung}

\section{Hintergrund}

Der Nutzen instrumenteller Gang- und Gleichgewichtsanalyse, zur Früherkennung von Stürzereignissen, wird aktuell kontrovers diskutiert.

\section{Fragestellung}

Untersucht wurde der Zusammenhang zwischen Variablen der statischen Posturographie, der instrumentellen Ganganalyse und klinischer Assessments mit dem Auftreten von Stürzereignissen, bei selbstständig lebenden älteren Personen.

\section{Methoden}

Basierend auf einem prospektiv aufgetretenen Sturz wurden 84 ältere Personen in „Stürzer“ und „Nichtstürzer“ klassifiziert. Variablen aus klinischen Assessments, der statischen Posturographie und der instrumentellen Ganganalyse wurden in Hinblick auf eine Assoziation mit prospektiven Stürzen evaluiert, dazu diente ein vorwärts schrittweises, binärer, logistisches Regressionsverfahren.

\section{Ergebnisse}

Stürzer zeigten eine signifikant kürzere monopedale Standphase bein Gehen und Rückwärtszählen, im Vergleich mit anterior-posterioren Schwankungen höheremedio-laterale Schwankungen, verstärkte schnelle mediolaterale Oszillationen und einen vergrößerten Koeffizient der Schwankungsrichtung während verschiedener statische posturographischer Tests. Frühere Stürzereignisse waren nicht signifikant assoziiert mit prospektiv erfassten Stürzen.

\section{Diskussion}

Variablen der statischen Posturographie und instrumenteller Ganganalyse zeigten bei selbstständig lebenden älteren Personen signifikante Assoziationen mit prospektiv erfassten Stürzen. 


\section{Keywords}

Postural balance

Gait

Accidental falls

Prognosis

Geriatric assessment

Schlüsselwörter

Balance

Gang

Akzidentelle Stürzereignisse

Prognose

Geriatrisches Assessment

Electronic supplementary material

The online version of this article (doi:10.1007/s00391-015-0885-0) contains supplementary material, which is available to authorized users.

The role of instrumented balance and gait assessment in screening for prospective fallers is controversially discussed. The aim of this study was to compare clinical assessments and instrumented balance and gait analysis for screening community dwelling older adults for prospective falls.

\section{Introduction}

Falls are a common cause of disability and hospitalization in older adults [1]. Approximately 1 in 3 community dwelling people aged 65 years or over falls at least once during a period of 1 year. High-risk patients for falling can be identified in clinics and other clinical settings and, consequently, effective interventions can be introduced [2,3]. The effectiveness of the interventions depends on whether they are applied to the correct population [4].

Determining the right interventions remains a challenge as falls are complex and caused by a combination of intrinsic and extrinsic factors [ 1,5$]$.

Currently, multifactorial risk assessments are recommended [4]. Widely used assessment methods to identify balance and mobility impairments in older people include balance assessment scales, such as the Berg balance scale (BBS) [6] and clinical measures, such as functional reach [7]. These are 
often combined with a geriatric assessment as described by Applegate et al. [8]. Together with these clinical and functional evaluations, instrumental gait analysis is a widely applied model for assessing fall prone elderly persons in research contexts and specialized facilities [9]. The combination of cognitive tasks and instrumental gait analysis has been shown to be a promising approach [10]. Additionally, the instrumental assessment of balance by force platforms is a widely used modality in research laboratories, with several variables computed from displacement of the center of pressure $(\mathrm{CoP})$. These variables have been investigated under different test conditions, such as standing with open and closed eyes [11]. The role of the instrumented assessment of balance in clinical decision-making has been recently reviewed [12-14]. Two reviews concluded that instrumented balance assessment remains controversial when trying to identify fallers $[13,15]$.

The aim of this study was to compare the association of variables derived from clinical assessments, including clinical measures of balance performance, static posturography and instrumented gait analysis with prospective falls. The hypothesis was that a model based on instrumented gait and balance analysis combined with geriatric assessment data could predict falls better than a model based solely on geriatric assessment data.

\section{Methods}

\section{Participants}

A total of 84 community dwelling older adults ( 22 men and 62 women) were recruited through a newspaper announcement (Table 1). Inclusion criteria were participants had to be 65 years or older, living independently in their own homes, able to walk $50 \mathrm{~m}$ with or without a walking aid, able to stand independently for $90 \mathrm{~s}$ and able to understand and follow verbal instructions. Exclusion criteria were acute or sub-acute diseases of the cardiovascular and respiratory systems and severe cognitive impairment with a mini-mental state examination (MMS) score $<10$ points. Many patients attending the falls clinic suffer from vestibular disorders; therefore, these patients were not excluded. The study was approved by the local ethics committee. All participants signed informed consent prior to the study.

\section{Table 1}

Participant characteristics and results of the clinical assessment 


\begin{tabular}{|c|c|c|c|c|}
\hline & $\begin{array}{l}\text { participants }(n \\
=75)\end{array}$ & $(n=49)$ & $(n=28)$ & (p-value) \\
\hline Age (years) & $79.1 \pm 6.2$ & $78.9 \pm 5.8$ & $\begin{array}{l}79.4 \pm \\
6.9\end{array}$ & 0.79 \\
\hline Height (cm) & $163.9 \pm 7.9$ & $163.8 \pm 9.06$ & $\begin{array}{l}164.1 \pm \\
5.6\end{array}$ & 0.63 \\
\hline Weight (kg) & $68.9 \pm 13.2$ & $66.1 \pm 11.2$ & $\begin{array}{l}70.5 \pm \\
14.1\end{array}$ & 0.22 \\
\hline MMS & $29.3 \pm 0.9$ & $29.3 \pm 0.8$ & $\begin{array}{l}29.1 \pm \\
1.1\end{array}$ & 0.32 \\
\hline GDS & $2.3 \pm 2.3$ & $2.1 \pm 2.1$ & $2.6 \pm 2.6$ & 0.28 \\
\hline $\begin{array}{l}\text { Tinetti balance } \\
\text { scale }\end{array}$ & $13.3 \pm 2.1$ & $13.3 \pm 2.1$ & $\begin{array}{l}13.4 \pm \\
2.2\end{array}$ & 0.74 \\
\hline Tinetti gait test & $11.4 \pm 1.7$ & $11.4 \pm 1.8$ & $11.3 \pm 1.6$ & 0.71 \\
\hline BBS & $49.6 \pm 5.9$ & $49.1 \pm 6.5$ & $\begin{array}{l}50.5 \pm \\
4.8\end{array}$ & 0.43 \\
\hline 5-Chair rise test (s) & $14.5 \pm 4.8$ & $14.7 \pm 5.6$ & $\begin{array}{l}14.3 \pm \\
2.7\end{array}$ & 0.62 \\
\hline $\mathrm{TuG}(\mathrm{s})$ & $9.7 \pm 3.5$ & $9.8 \pm 3.8$ & $9.5 \pm 2.8$ & 0.91 \\
\hline $\begin{array}{l}\text { Peripheral } \\
\text { neuropathy }\end{array}$ & $0.59 \pm 0.27$ & $0.59 \pm 0.28$ & $0.61 \pm 27$ & 0.77 \\
\hline Visual acuity & $0.41 \pm 0.23$ & $0.41 \pm 0.24$ & $\begin{array}{l}0.42 \pm \\
.21\end{array}$ & 0.98 \\
\hline $\begin{array}{l}\text { Falls in previous } \\
12 \text { months }^{\mathrm{a}}\end{array}$ & $0(0-5)$ & $0(0-4)$ & $1(0-5)$ & 0.12 \\
\hline \multicolumn{5}{|c|}{$\begin{array}{l}\text { Values are mean } \pm \mathrm{SD} \text {, the Mann-Whitney test was used for between groups } \\
\text { comparisons }\end{array}$} \\
\hline \multicolumn{5}{|c|}{$\begin{array}{l}M M S \text { mini-mental state, } G D S \text { geriatric depression scale, } B B S \text { Berg balance scale, } \\
\text { Tu } G \text { timed up and go test }\end{array}$} \\
\hline
\end{tabular}

AQ1

\section{Assessment}

All participants were examined by a physician and a physiotherapist specialized in geriatrics. The assessment consisted of taking the patient history, physical examination, clinical balance and gait assessment, MMS [16], 15-item geriatric depression scale (GDS) [17], timed up and go test 
(TuG) [18], Tinetti balance scale ([19], 5-chair rise test [20], BBS [6], assessment of visual acuity [21] and screening for peripheral diabetic neuropathy [22].

\section{Fall history}

The history of falls in the previous year was collated during the patient history. A fall was defined according to the criteria of the prevention of falls network Europe (ProFaNE) group [23].

\section{Instrumentation}

Instrumented gait analysis

Gait variables were quantified with GAITRite $\AA$ instrumentation (CIR Systems, Clifton, NJ) consisting of an instrumented walkway $(6.9 / 0.9 \mathrm{~m})$. The active area contains 23,040 pressure sensors with a spatial resolution of $1.27 \mathrm{~cm}$. Data were sampled at $120 \mathrm{~Hz}$ and processed using GAITRite Gold® software. The reliability of the GAITRite(Csystem has been confirmed previously [24].

\section{Posturography}

Anteroposterior (AP) and mediolateral (ML) CoP trajectories were estimated with a SATEL $®($ Satel, Blagnac, France) force platform $(480 \times 480 \times 65 \mathrm{~mm})$ with three strain gauges set in a triangular formation. Force data were sampled at $40 \mathrm{~Hz}$ and filtered with a $25 \mathrm{~Hz}$ low pass second order Butterworth filter to cancel out electric perturbations by the SATEL® software.

\section{Variables}

All variables calculated from the force plate and the GAITRite are shown in supplementary file 1 .

\section{Experimental set-up}

The test conditions (e.g. lighting, room temperature and noise level) were standardized before the tests. All trials were conducted by the same two researchers. The experimental set-ups [25, 26] have been described elsewhere. The instrumented gait analysis consisted of normal walking and counting backwards from 50 to $1(\mathrm{C})$. The assessment was carried out according to the international recommendations for spatiotemporal gait analysis [9] and static posturography [11]. 


\section{Follow-up}

The number of falls during the 8 months after the measurements was recorded via bimonthly telephone interviews and fall diaries filled out by the participants and collected after 8 months.

\section{Data processing}

Offline processing of posturography and gait analysis variables was performed using Matlab R2012b (MathWorks, Nantic, CT). Median values were used for further analysis. The gait analysis variables were averaged for left and right feet together. All variables were z-transformed.

\section{Statistical analysis}

To select the variables most strongly associated with prospective falls, a forward stepwise binary logistic regression procedure (Wald criteria) was performed. Variables which showed multicolinearity and significant autocorrelations with other variables that had a stronger association with prospective falls were removed from the model, to reduce the model to a set that provides the best possible understanding of the principle factors involved in predicting falls. This procedure reduced the number of variables to a maximum of five variables for each model. Three models were calculated: the first model was based on variables derived from clinical assessments, the second model was based on measurements from posturographic and instrumented gait analysis (supplementary file 2) and the third model was based on both assessments and variables from model two. Significance was set at $p \leq 0.05$.

Naegelkerkes $r^{2}\left(r^{2}\right)$ and positive and negative predictive values (PPV and $\mathrm{NPV}$ ) were calculated for each model where $\mathrm{r}^{2}$ is a measure of how well the selected model correlates with the actual occurrence of prospective falls. The PPV and NPV were calculated as follows:

$$
\begin{gathered}
P P V=\frac{\text { numberoftruepositives }}{\text { numberofpositivecalls }} \\
N P V=\frac{\text { numberoftruenegatives }}{\text { numberofnegativecalls }}
\end{gathered}
$$


The regression coefficient $\beta$ and the corresponding odds ratio (exponent $\beta$ ) with $95 \%$ confidence intervals $(95 \% \mathrm{CI})$ were calculated as indicators of the directional relationship between the respective variable and the risk of prospective falls. A negative $\beta$ and an exponent $\beta<1$ indicate that the risk for prospective falls increases if the variable decreases, a positive $\beta$ and exponent $\beta>1$ indicate that the risk of prospective falls increases if the variable increases. In a clinical setting, cut-off scores are a useful measure to differentiate those individuals with an elevated risk for falls from those without. To determine which magnitude of a variable would predict falls, receiver operating characteristics (ROC) curves were calculated and the coordinate points were used to determine the cut-off. A coordinate point with a sensitivity of 0.8 was chosen as the cut-off for each variable. The intrasession reliability of the posturography variables was investigated using interclass correlation coefficients 2-k (ICC) and the standard error of the measurement (SEM). Differences at baseline between the drop-outs and the rest of the sample were assessed using the Mann-Whitney U-test. All statistical analyses were done using SPSS 20 (IBM, Armonk, NY).

\section{Results}

During the follow-up nine participants dropped out leaving the data from 75 participants for analysis. The characteristics of the participants and results from the clinical assessment are shown in Table 1. The drop-outs had a significantly lower MMS score than the rest of the participants (drop-outs $28.17 \mathrm{SD}=0.75$ and retained 29.31 $\mathrm{SD}=0.97, p=0.003$ ). No other differences were observed between the drop-outs and the participants who remained in the study (data not shown).

Descriptive data and group effects for all instrumented assessment variables are shown in supplementary file 1 . The factors identified as being most significantly associated with prospective falls are shown in Tables 2 and 3 . The results of model 1 revealed that none of the assessment variables were significantly associated with the occurrence of prospective falls (Table 3 ). The results of model 2 revealed that the following variables were significantly associated with prospective falls: reduced single support time (SST) during dual-task walking measured with instrumented gait analysis and increased fast oscillations in the ML plane (MLFreq > $2 \mathrm{~Hz}$ ), a higher coefficient of sway direction (Coeff) during standing with eyes open (EO) and a higher ratio between the AP and ML amplitudes (AmpML/AmpAP) during narrow 
standing with EO (NEO) measured with posturography (Table 3). Model 3 revealed that when combining the clinical assessments with instrumented analysis, the number of falls in the preceding 12 months were insignificantly associated with prospective falls (Table 3 ).

\section{Table 2}

Comparison of the three models obtained by binary logistic regression

\begin{tabular}{|l|l|l|l|}
\hline & Model 1 & Model 2 & Model 3 \\
\hline $\mathrm{R}^{2}$ & 0.12 & 0.50 & 0.55 \\
\hline$\Delta \mathrm{R}^{2}$ & - & 0.38 & 0.05 \\
\hline Correct classification all (\%) & 68 & 75 & 85.3 \\
\hline PPV (\%) & 28 & 66 & 85 \\
\hline NPV (\%) & 89 & 80 & 85 \\
\hline$\triangle R^{2}$ delta ${ }^{2} ; P P V$ positive predictive Value; $N P V$ negative predictive value; $R^{2} \mathrm{r}^{2}$ \\
\hline
\end{tabular}

Table 3

Regression coefficients $\beta$, significance (Sig.) and exponent $\beta$ (Exp $\beta$ ) for each predictor ir by binary logistic regression

\begin{tabular}{|c|c|c|c|c|c|c|}
\hline & $\begin{array}{l}\text { Model } \\
1\end{array}$ & & & $\begin{array}{l}\text { Model } \\
2\end{array}$ & & \\
\hline Predictor & B & Sig. & $\begin{array}{l}\operatorname{Exp} \beta(95 \% \\
\text { CI) }\end{array}$ & B & Sig. & $\begin{array}{l}\operatorname{Exp} B(95 \% \\
\text { CI) }\end{array}$ \\
\hline $\begin{array}{l}\text { Falls in previous } \\
12 \text { months (n) }\end{array}$ & 0.520 & 0.063 & $\begin{array}{l}1.682 \\
(0.972-2.913) \\
\text { AQ2 }\end{array}$ & - & - & - \\
\hline BBS & 0.861 & 0.083 & $\begin{array}{l}2.366 \\
(0.893-6.272)\end{array}$ & - & - & - \\
\hline $\begin{array}{l}\text { Tinetti balance } \\
\text { scale }\end{array}$ & $\overline{0} .592$ & 0.171 & $\begin{array}{l}0.553 \\
(0.237-1.291)\end{array}$ & - & - & - \\
\hline Coeff EO & - & - & - & 1.277 & 0.002 & $\begin{array}{l}3.586 \\
(1.597-8.054)\end{array}$ \\
\hline $\begin{array}{l}\text { AmpML/AmpAP } \\
\text { NEO }\end{array}$ & - & - & - & 1.083 & 0.007 & $\begin{array}{l}2.953 \\
(1.342-6.498)\end{array}$ \\
\hline
\end{tabular}

$B B S$ Berg balance scale, Coeff coefficient of sway direction, AmpML/AmpAP ratio of amplitudes, MLFreq $>2 \mathrm{~Hz}$ the energy content within a high frequency band $(>2 \mathrm{~Hz}$ ) $E O$ standing with eyes open, $N E O$ narrow standing with eyes open, $C$ walking while c 


\begin{tabular}{|c|c|c|c|c|c|c|}
\hline & $\begin{array}{l}\text { Model } \\
1\end{array}$ & & & $\begin{array}{l}\text { Model } \\
2\end{array}$ & & \\
\hline Predictor & B & Sig. & $\begin{array}{l}\operatorname{Exp} \beta(95 \% \\
\text { CI })\end{array}$ & B & Sig. & $\begin{array}{l}\operatorname{Exp} \beta(95 \% \\
\text { CI })\end{array}$ \\
\hline $\begin{array}{l}\text { MLFreq }>2 \mathrm{~Hz} \\
\text { EO }\end{array}$ & - & - & - & 1.328 & $\begin{array}{l}< \\
0.001\end{array}$ & $\begin{array}{l}3.773 \\
(1.794-7.938)\end{array}$ \\
\hline $\begin{array}{l}\text { Single support } \\
\text { time C }\end{array}$ & - & - & - & $\overline{0} .828$ & 0.050 & $\begin{array}{l}0.437 \\
(0.191-1.001)\end{array}$ \\
\hline
\end{tabular}

$B B S$ Berg balance scale, Coeff coefficient of sway direction, AmpML/AmpAP ratio of amplitudes, $M L F r e q>2 \mathrm{~Hz}$ the energy content within a high frequency band $(>2 \mathrm{~Hz})$ $E O$ standing with eyes open, $N E O$ narrow standing with eyes open, $C$ walking while c

Model 1 showed a lower PPV of $28 \%$ as opposed to models 2 and 3 (66-80 \%). All models showed a high NPV (80-89\%) (Table 2 ). The following cut-offs were found to indicate an $80 \%$ risk for future falls: an SST of less than $0.42 \mathrm{~s}$, an AmpML/AmpAP ratio greater than 0.68, a Coeff greater than -0.19 and MLFreq $>2 \mathrm{~Hz}$ greater than 0.75 . However, the specificity at these cut-offs was low, ranging from 33-58 \% (supplementary file 3 ). The ICC of the selected variables ranged between 0.73-0.92 and the SEM between 0.13-8.83 (supplementary file 2).

\section{Discussion}

Variables derived from instrumented assessment of gait and balance and the history of falls are predictors of prospective falls in a population of community dwelling older adults. Those with an elevated risk of falling in the future displayed a significantly shorter SST during $\mathrm{C}$, an increased AmpML/AmpAP, an increased amount of MLFreq $>2 \mathrm{~Hz}$ and a greater Coeff. These results are in contrast to studies on community dwelling older adults showing that clinical assessment data were good predictors of falls [14, 27$]$. These differences could be explained by the relative mild levels of balance impairment in this population (Table 1). Instrumented assessment might be paramount in detecting an elevated risk of falls in elderly people with mild balance or gait impairments. In the population studied here a single support time of less than $0.42 \mathrm{~s}$ indicates a risk for future falls of $80 \%$. This is below values reported for healthy persons $(0.44-0.45 \mathrm{~s}$ [24]) but above those reported for fallers and users of walking aids $(0.33 \mathrm{~s}$ and $0.38 \mathrm{~s}$, respectively) $[28,29]$. The differences might also be explained by the age of the study population, the health status or the content of the geriatric assessment, such as 
the selected balance tests [29]. Recent research results support the use of dual-task walking tests to identify older fallers $[10,30]$.

AQ3

Critical values for an increase in ML sway were identified and AmpML/AmpAP, MLFreq $>2 \mathrm{~Hz}$ and Coeff may be useful as predictors for prospective falls. These results highlight the relationship between increased ML sway and risk for future falls, with further studies supporting this association [15]. Commonly used measures, such as mean sway velocity of the CoP, the area of sway or the length of sway of the CoP [11] were not included in the final models as they were not associated with prospective falls, multicolinear or autocorrelated to stronger predictors. The variables retained in the final models were measured during EO and NEO. This is in agreement with other studies [12] but is in contrast to the results of studies using EC tests [15]. Merlo et al. showed that EO was a feasible test to identify fallers retrospectively [12] and the results of this study show that prospective falls can also be identified with this test. Whether the different results between this approach and others $[11,13,15]$ can be attributed to study protocol, study population or the variables derived from the assessment have to be investigated in future studies.

\section{AQ4}

When using instrumented gait and balance analysis a test battery consisting of EO and NEO tests on the force plate and $\mathrm{C}$ on the instrumented walkway are recommended. The test battery can be implemented in working routine in research laboratories or fall clinics, since its duration is around $10 \mathrm{~min}$, provided the necessary equipment and training are available.

\section{Limitations}

The same subjects were used both to derive the models and then to evaluate their properties. The models were derived from a small sample size. To validate these models and derive precise cut-offs, with high sensitivity and specificity, they should be subject to independent testing with a larger study population. Other important factors such as gender, medical history, and fall circumstances, use of walking aides or uptake of medications must be considered. Other approaches for predictor selection, besides automated statistical techniques should be taken into account: A hierarchical approach for which cheap tests (such as previous falls), or simpler predictors (such as area of sway) enter a model more easily than complicated tests, should be 
considered.

\section{Conclusion}

Instrumented assessments can identify prospective fallers in a population of community dwelling older adults. While accurate identification of fallers may require more sophisticated instrumentation than currently available, in most clinical settings our model appears suited not only for research laboratories but for any clinical setting where force-platforms and instrumented gait assessments are available. Considering the predicted rise in falls due to the demographic shift in population over the next decades, investing in the instrumentation and staff training may prove a prudent choice compared to the status quo. The models must be validated in a larger, independent population.

\section{Practitioner's summary}

- Instrumented assessments can identify prospective fallers in a population of community dwelling older adults.

- The models and cut-off scores must be validated before instrumented assessment can be recommended for use in daily practice.

Compliance with ethical guidelines

Conflict of interest C.M. Bauer, I. Gröger, R. Ruprecht, V.L. Marcar and K.G. Gaßmann declare that there no conflicts of interest.

The study was approved by the local ethics committee and was carried out in accordance with national law and the Helsinki Declaration of 1975 (in its current revised form). All participants signed informed consent prior to the study.

\section{Electronic supplementary material}

(DOCX $23 \mathrm{~kb}$ )

(DOC $47 \mathrm{~kb})$ 
(DOCX $36 \mathrm{~kb})$

\section{References}

1 Berry SD, Miller RR (2008) Falls: epidemiology, pathophysiology, and relationship to fracture. Curr Osteoporos Rep 6:149-154

2 Hill KD, Moore KJ, Dorevitch MI et al (2008) Effectiveness of falls clinics: an evaluation of outcomes and client adherence to recommended interventions. J Am Geriatr Soc 56:600-608

3 Gillespie LD, Robertson MC, Gillespie WJ et al (2012) Interventions for preventing falls in older people living in the community. Cochrane Database Syst Rev 9:CD007146

4 Kenny RAM, Rubenstein LZ, Tinetti ME et al (2011) Summary of the updated American Geriatrics Society/British Geriatrics Society Clinical Practice Guideline for prevention of falls in older persons. J Am Geriatr Soc 59:148-157

5 Kannus P, Sievanen H, Palvanen M et al (2005) Prevention of falls and consequent injuries in elderly people. Lancet 366:1885-1893

6 Berg K, Wood-Dauphinee S, Williams JI (1995) The balance scale: reliability assessment with elderly residents and patients with an acute stroke. Scand J Rehabil Med 27:27-36

7 Duncan PW, Weiner DK, Chandler J et al (1990) Functional reach: a new clinical measure of balance. J Gerontol 45:M192-M197

8 Applegate WB, Blass JP, Williams TF (1990). Instruments for the functional assessment of older patients. N Engl J Med 322:1207-1214

9 Kressig RW, Beauchet O, European GAITRite Network Group (2006) Guidelines for clinical applications of spatio-temporal gait analysis in older adults. Aging Clin Exp Res 18:174-176

10 Kressig RW, Herrmann FR, Grandjean R et al (2008) Gait variability 
while dual-tasking: fall predictor in older inpatients? Aging Clin Exp Res 20:123-130

11 Ruhe A, Fejer R, Walker B (2010) The test-retest reliability of centre of pressure measures in bipedal static task conditions - a systematic review of the literature. Gait Posture 32:436-445

12 Merlo A, Zemp D, Zanda E et al (2012) Postural stability and history of falls in cognitively able older adults: the Canton Ticino study Gait Posture 36:662-666

13 Nardone A, Schieppati M (2010) The role of instrumental assessment of balance in clinical decision making. Eur J Phys Rehabil Med 46:221-237

14 Bongue B, Dupré C, Beauchet $\mathrm{O}$ et al (2011) A screening tool with five risk factors was developed for fall-risk prediction in community-dwelling elderly. J Clin Epidemiol 64:1152-1160

15 Piirtola M, Era P (2006) Force platform measurements as predictors of falls among older people-a review. Gerontology 52:1-16

16 Folstein MF, Folstein SE, McHugh PR (1975) "Mini-mental state": a practical method for grading the cognitive state of patients for the clinician. J Psychiatr Res 12:189-198

17 Sheikh JI, Yeswage JA (1986) Geriatrci depression scale (GDS): recent evidence and development of a shorter version. Clin Gerontol 5:165-173

18 Podsiadlo D, Richardson S (1991) The timed "Up and Go": a test of basic functional mobility for frail elderly persons. J Am Geriatr Soc 39:142-148

19 Tinetti ME (1986) Performance oriented assessment of mobility problems in elderly patients. J Am Geriatr Soc 34:119-128

20 McCarthy EK, Horvat MA, Holtsberg PA et al (2004) Repeated chair stands as a measure of lower limb strength in sexagenarian women. J Gerontol Ser A-Biol Sci Med Sci 59:1207-1212 
21 Davidson D, Eskridge J (1977) Reliability of visual acuity measures of amblyopic eyes. Am J Optom Physiol Opt 54:756-766

22 Lunetta M, Le Moli R, Grasso G et al (1998) A simplified diagnostic test for ambulatory screening of peripheral diabetic neuropathy. Diabetes Res Clin Pract 39:165-172

23 Lamb SE, Jørstad-Stein EC, Hauer K et al (2005) Development of a common outcome data set for fall injury prevention trials: the Prevention of Falls Network Europe consensus. J Am Geriatr Soc 53:1618-1622

24 van Uden C, Besser M (2004) Test-retest reliability of temporal and spatial gait characteristics measured with an instrumented walkway system (GAITRite(R)). BMC Musculoskelet Disord 5:13

25 Bauer C, Groeger I, Glabasnia A et al (2010) First results of the evaluation of a falls clinic. Int J Gerontol 4:130-136

26 Bauer C, Groeger I, Rupprecht R et al (2008) Intrasession reliability of force platform parameters in community-dwelling older adults. Arch Phy Med Rehabil 89:1977-1982

27 Murphy MA, Olson SL, Protas EJ et al (2003) Screening for falls in community-dwelling elderly. J Aging Phys Act 11:66-80

28 Paterson K, Hill K, Lythgo N (2011) Stride dynamics, gait variability and prospective falls risk in active community dwelling older women. Gait Posture 33:251-255

29 Liu H, McGee M, Wang W et al (2009) Comparison of gait characteristics between older rolling walker users and older potential walker users. Arch Gerontol Geriatr 48:276-280

30 Bridenbaugh SA, Kressig RW (2015) Motor cognitive dual tasking: early detection of gait impairment, fall risk and cognitive decline. $\mathrm{Z}$ Gerontol Geriatr 48:15-21 